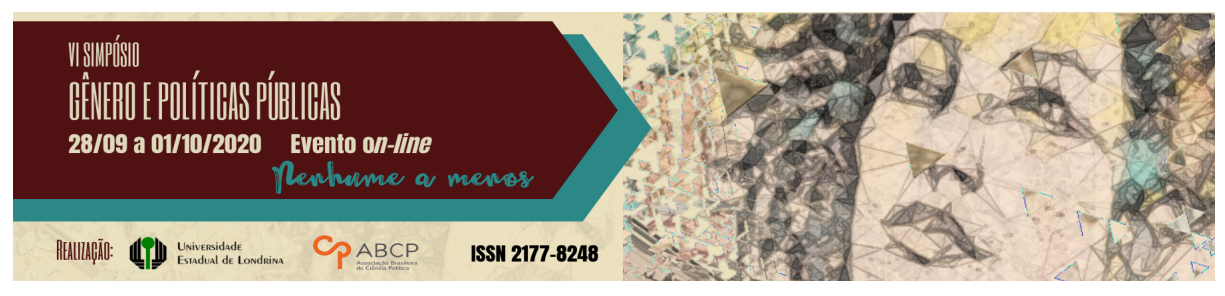

\title{
Política de enfrentamento às violências de gênero contra às mulheres no Brasil: um olhar a partir da sua implementação para às mulheres residentes em favelas
}

\author{
Ariana Kelly dos Santos ${ }^{1}$
}

\section{Resumo}

Em 2018, às mulheres residentes no país representavam 51,7\% da população brasileira, somando mais de 108 milhões, destas, mais de 55\% eram mulheres negras. Neste mesmo ano, foram assassinadas 4.519 mulheres, sendo destas $68 \%$ negras. Das 60 milhões de mulheres negras que constituem a população brasileira, 10,5\% residem em favelas e vivem em condição de pobreza. Tais dados demonstram parte da diversidade das mulheres brasileiras, nesse sentido, nos questionamos se o principal instrumento existente no país para o enfrentamento à violência contra às mulheres tem abrangido as mulheres em sua diversidade. Assim, o presente artigo é resultado da pesquisa que objetivou analisar como vem sendo a implementação da Política Nacional de Enfrentamento à Violência Contra às Mulheres, para as que residem em territórios de favelas. Objetivamos apresentar os avanços e desafios dessa política, a partir de Manguinhos, território de favela localizado na zona norte da capital do Rio de Janeiro.

Palavras-chave: violência de gênero; territórios de favela; mulheres negras.

\section{Policy to confront gender-based violence against women in Brazil: a look from its implementation to women living in slums}

\footnotetext{
1 Assistente Social, Doutoranda do Programa de Pós-graduação em Serviço Social da Universidade Federal do Rio de Janeiro -PPGSS/UFRJ. E-mail: arianaksantos@gmail.com.
}

GT 18 - Políticas públicas de gênero no Brasil do século XXI: avanços e desafios 


\begin{abstract}
In 2018, women residing in the country represented $51.7 \%$ of the Brazilian population, adding up to more than 108 million, these, more than $55 \%$ were black women. In the same year, 4,519 women were murdered, $68 \%$ of whom were black. Of the 60 million black women who adopt a Brazilian population, $10.5 \%$ live in slums and live in poverty. Such data demonstrate part of the diversity of Brazilian women, in this sense, we question whether the main instrument existing in the country to confront violence against women has covered women in their diversity. Thus, this article is the result of research that aimed to analyze how the National Policy to Combat Violence Against Women has been implemented for those who live in slum territories. We aim to present the advances and challenges of this policy, starting from Manguinhos, a slum territory located in the north of the capital of Rio de Janeiro.
\end{abstract}

Keywords: gender violence; slum territory; black women.

\title{
Introdução
}

O enfrentamento da violência contra as mulheres no Brasil, deve ser realizado tendo como base os princípios, diretrizes e conceitos estabelecidos na Política Nacional de Enfrentamento à Violência Contra as Mulheres (PNEV), criada em 2011, a partir do I Plano Nacional de Políticas para as Mulheres realizado em 2004. As ações de enfrentamento ao fenômeno já existem desde os fins da década de 1980, mas é somente a partir de 2003 que as ações a nível federal se tornam mais vigorosas e organizadas. Mas, as mulheres são diversas, será que a Política em questão responde as necessidades de todas as mulheres brasileiras de forma igual?

Os territórios de favela são marcados desde a sua origem pela violação de direitos da população pelo Estado. No fim de 1800 quando a primeira favela no Rio de Janeiro surgiu, o fato ocorre pela expulsão da população pobre, em maioria negra, dos centros urbanos em detrimento da valorização econômica (CAMPOS, 2012). Somado a isso, essa população que foi expulsa dos centros urbanos, região que oferecia maior acesso a trabalho, foi excluída de ter acesso a esse direito, assim como também ao direito a terras, o direito a ocupar cargos na 
administração pública, ou seja, a maioria da população que foi ocupar esse espaço territorial foi destituída de direitos, não consideradas como cidadãs/ãos.

$\mathrm{Na}$ atualidade, os territórios de favela não se modificaram, o Estado continua violando direitos, para nós se amplia o Estado penal e se reduz as políticas sociais (WACQUANT, 2003, p. 123), resultando em nossa morte cultural e vida.

É dentro desse contexto que se pretende investigar como vem sendo implementada a PNEV (2011). Como é possível implementar uma política pública de enfrentamento à violência contra as mulheres, para as que residem em territórios de favela, tendo estes a configuração de violação de direitos perpetrada pelo Estado?

A pesquisa teve como ponto de partida para a análise a hipótese que a PNEV (2011) não tem levado em consideração as necessidades das mulheres residentes em favela, desconsiderando as diversas formas de opressões que nós vivenciamos e as configurações que marcam o território em que vivemos.

Entre o compasso e o descompasso das políticas públicas de enfrentamento à violência contra as mulheres no Brasil

O tema da violência contra às mulheres, no Brasil, ganha maior visibilidade a partir do fim da década de 1970 e início de 1980. O assassinato de duas mulheres da elite brasileira, Angela Diniz e Eliane de Grammont, por seus companheiros, chocam a sociedade e impulsionam as primeiras campanhas públicas contra à violência de gênero que atinge as mulheres, especialmente a doméstica e familiar, exigindo ações interventivas do Estado no enfrentamento ao fenômeno.

Em resposta, na década de 1980, se criaram as primeiras Delegacias Especializadas de Atendimento à Mulher- DEAM e o Conselho Nacional de Direitos da Mulher-CNDM (PINTO, 2003 apud SANTOS, 2011). A Carta Magna brasileira de 1988, formalmente, 
contribuiu para o avanço e o reconhecimento de direitos importantes, além disso, seu processo constituinte teve a participação ativa das mulheres ${ }^{2}$. Este documento estabeleceu a igualdade entre os sexos e passou a reconhecer que a violência no âmbito da família era um problema que o Estado tinha a responsabilidade de coibir.

A década de 1990, no que tange o enfrentamento à violência contra às mulheres pelo Estado, foi uma década perdida, marcada pela introdução da ideologia neoliberal no país, iniciaram-se processos de privatização de diversas instituições estatais, cortes financeiros para as políticas sociais e desmobilização de movimentos sociais. Até 2003, as principais políticas públicas de enfrentamento à violência contra às mulheres, se localizavam no campo da segurança pública com as DEAMs e na assistência com as Casas-abrigo (CARVALHO, 2015, p. 52).

Este cenário só se altera a partir de 2003, na presidência de Luiz Inácio Lula da Silva, através da Lei 10.683 de 28 de maio de 2003 que cria a Secretaria Especial de Políticas para as Mulheres com status de Ministério e orçamento próprio, iniciando um planejamento mais articulado, integrado e vigoroso para desenvolver políticas públicas para às mulheres no país.

Basterd (2011) aponta algumas respostas do Estado a partir de 2003, para o enfrentamento à violência contra as mulheres tendo como base as preocupações e recomendações da Convenção Cedaw e do capítulo III da Convenção de Belém do Pará, que estabelece os deveres do Estado: no campo legislativo se teve um notável avanço nas legislações relativas ao enfrentamento da violência doméstica e familiar contra as mulheres, sendo algumas delas: a criação da Lei 10.778, de 24

\footnotetext{
2 As mulheres brasileiras, em 1987, enviaram a Assembleia Nacional Constituinte um documento denominado "Carta das Mulheres aos Constituintes" no qual reivindicaram a igualdade legal perante os homens e elencaram suas demandas em várias áreas, como saúde, trabalho, educação, cultura etc. É possível acessar a carta pelo link: http:/ / www2.camara.leg.br/atividade-

legislativa/legislacao/Constituicoes_Brasileiras/constituicao-cidada/constituintes/aconstituinte-e-as-mulheres/Constituinte\%201987-1988-

Carta\%20das\%20Mulheres\%20aos\%20Constituintes.pdf . Acesso em 05 de outubro de 2018.
} 
de novembro de 2003 que estabeleceu a notificação compulsória nos serviços de saúde, públicos e privados dos casos de violência contra as mulheres atendidas, sendo uma notificação de caráter sigiloso, que tem como objetivo principal dar visibilidade ao fenômeno, fornecendo dados para que o Estado possa promover de forma mais qualificada as políticas públicas.

Em 2004 ocorrem alterações importantes no código penal, se tipificou a violência doméstica como crime, tendo como vítima qualquer pessoa da família; em 2005 se alterou artigos considerados discriminatórios, como a extinção da punição do estuprador caso se casasse com a vítima; foi retirada do código a expressão "mulher honesta" definida a partir de conceitos morais; foi revogado o Art. 240 relativo ao crime de adultério, que foi utilizado culturalmente contra as mulheres; em 2009 a alteração no Código Penal Brasileiro do Título VIDos crimes contra os costumes para Dos crimes contra a dignidade sexual, percebendo que a preocupação anterior era com a dignidade social das famílias e não com a integridade das mulheres; em 2018 com a Lei 13.718, de setembro de 2018 se tipificou os crimes de importunação sexual que antes não eram regulamentados.

Um progresso importante ocorrido nesse período foi a constituição da primeira legislação específica de combate à violência doméstica e familiar contra as mulheres, a Lei 11.340, de 07 de agosto de 2006, conhecida como Lei Maria da Penha, que é fruto da responsabilização do País por não cumprir os tratados internacionais assinados.

A Lei Maria da Penha, traz em sua redação conceitos importantes apontados pela Convenção de Belém do Pará, como por exemplo a definição expressa do que é violência contra a mulher e suas diferentes formas. Isso se torna importante porque anterior a legislação somente violência física era considerada violência.

A Convenção de Belém do Pará destaca em seu Art. $1^{\circ}$ que violência contra a mulher é "qualquer ato ou conduta baseada no 
gênero, que cause morte, dano ou sofrimento físico, sexual ou psicológico à mulher, tanto na esfera pública como na esfera privada"; com a lei esse tipo de crime sendo no campo da violência doméstica e familiar sai do rol dos delitos de menor potencial ofensivo e se torna uma grave violação de direitos humanos. São criados Juizados especiais para julgar os casos de violência doméstica e familiar contra as mulheres e proibi o uso de medida alternativa de penas pecuniárias como punição. Se reconhece a violência doméstica e familiar em qualquer relação íntima de afeto independentemente de orientação sexual, também abrange as mulheres trans, o que evidencia o reconhecimento da diversidade das mulheres.

Essa legislação é uma das mais avançadas do mundo no campo, construída na perspectiva de integração dos poderes e dos entes federativos, que passa pelas áreas de prevenção, assistência, acesso à justiça, medidas de urgência, dentre outros aspectos, na perspectiva de que o Estado possa incidir no fenômeno da violência doméstica e familiar contra as mulheres.

No âmbito dos órgãos e mecanismos institucionais, no fim de 2010 existiam Secretarias de Políticas para às Mulheres em 23 estados brasileiros; no que diz respeito aos serviços especializados de atendimento a mulheres em situação de violência, entre 2003 a 2014 ocorreu um aumento de mais de 300\%, crescendo de 332 para 1256 serviços, sendo ainda as Delegacias os serviços com maior percentual de aumento (CARVALHO, 2015, p. 61).

Embora tenha ocorrido um aumento significativo de serviços, isso não representou a existência desses nem em $2 \%$ dos municípios brasileiros, uma vez que se tem 5.570 municípios e os serviços estavam concentrados majoritariamente nas capitais e regiões metropolitanas, o que revela a distribuição geográfica desigual e a dificuldade das mulheres que vivem em regiões mais distante terem acesso à política (Comissão Parlamentar Mista de Inquérito, 2012, p. 124). 
Ocorreram avanços no que diz respeito a estrutura dos serviços, produção de referenciais teóricos, mudança de legislações, mas se pode notar que a política para às mulheres não se estabeleceu como uma política de Estado e sim de governo, mantendo a sua condição de precariedade. A partir do processo eleitoral de 2014, com a formação de um congresso nacional mais conservador da história desde 1964 iniciase um ataque aos poucos direitos conquistados pela classe trabalhadora desde 1988, que atinge profundamente as políticas para as mulheres.

No estado do Rio de Janeiro, desde 2014 conforme aponta Pougy (2017) os serviços para as mulheres vem sendo desmantelados:

Os serviços de atendimento às mulheres no Rio de Janeiro estão fenecendo desde 2014, quando os rearranjos eleitoreiros para o executivo e legislativo estadual e federal - consentiram em rifar a área de políticas para as mulheres para partidos políticos com baixa tradição na área específica ou mesmo no campo dos direitos humanos. A frágil estabilidade com que a Subsecretaria de Políticas para Mulheres, vinculada a então Secretaria de Estado de Assistência Social e dos Direitos Humanos, se organizava, junto a outras Superintendências, como a Superintendência de Direitos individuais, coletivos e difusos, responsável pelo programa Rio Sem Homofobia, revela uma concepção de cidadania afinada ao modelo patriarcal, no qual a opressão a todas as identidades de gênero que não correspondam ao padrão heterossexual, macho, branco e rico deva ser reprimido (POUGY, 2017, P. 10)

Nesse contexto a pasta da mulher passa por inúmeras trocas de gestoras e profissionais, em quatro anos passando pela pasta 07 gestoras, entre o fim de 2014 à 2016 às profissionais dos serviços de atendimento à mulheres em situação de violência receberam seus salários atrasados, chegando ao ápice de ficarem mais de cinco meses sem receber qualquer valor remuneratório, e dos quatro CEAMs coordenados pelo governo estadual, três foram fechados por algum período nesses meses, sendo a Casa da Mulher de Manguinhos e o 
CIAM Baixada, que se localizam em territórios periféricos, estando fechados até o momento ${ }^{3}$.

Nesse cenário já nefasto e que dava indícios de como as forças políticas estavam se rearticulando, em 2015 ocorre a fusão das pastas da SPM, Secretaria de Políticas de Promoção da Igualdade Racial-SEPPIR e Direitos Humanos formando um único Ministério, o das Mulheres, da Igualdade Racial e dos Direitos Humanos, o que é um retrocesso e não contribui para manter a coalisão do governo com os demais partidos. Em seguida ocorre a destituição da primeira mulher no Brasil a ser eleita para a Presidência da República, realizado através de "um golpe jurídico, parlamentar e midiático com conteúdo misógino" (POUGY, 2017, p. 11).

Nesse cenário as taxas que expressam o assassinato de mulheres no Brasil regressam, tendo em 2016 o maior aumento de dez anos, sendo 4.645 mulheres vítimas de homicídio no país (ATLAS DA VIOLÊNCIA, 2018). Segato (2016, p. 35) aponta que está em curso no Brasil o retorno do discurso moral da política dos proprietários, construindo um novo tempo de moralismo cristão familista, destaca que o impeachment da primeira presidenta eleita ocorreu no congresso nacional com uma maioria de votos declarados publicamente em nome de Deus e pelo bem da família.

Na atualidade vemos o Ministério dos Direitos Humanos e da Família, sem projeto e programas que possam com o rigor que o tema necessita atender as mulheres em sua diversidade e enfrentar às diversas violências vivenciadas.

3 Os equipamentos foram fechados em 2016 e não reabriram. 


\section{Manguinhos/RJ e o Acesso das Mulheres às Políticas Públicas de Enfrentamento à Violência de Gênero}

Em Manguinhos, território de favela, localizado na zona norte do município do Rio de Janeiro, em 2010, foi fundada a Casa da Mulher de Manguinhos, Centro de Referência de Atendimento à Mulheres, primeiro equipamento do governo estadual especializado em atender esse público em um território de favela. Inicialmente a instituição tinha como premissa fundamental a promoção e o fortalecimento da cidadania das mulheres, atuando como serviço de informação, orientação e encaminhamentos para a rede de equipamentos que executam as políticas sociais; Após dois anos, a instituição passou a ser reconhecida como especializada para o atendimento às mulheres em situação de violência.

Manguinhos, em sua origem, era um espaço formado por manguezais, um local cercado por ilhas e mangues que formava um tipo de recuo no modelo de uma concha da Bahia de Guanabara, entre 1700 a 1800 era uma região predominantemente rural voltada para a produção de alimentos consumidos no próprio Rio de Janeiro (OLIVEIRA, 2016).

Enquanto espaço de habitação e moradia se desenvolve a partir de 1899 com a construção do Instituto Soroterápico Federal, hoje Fundação Oswaldo Cruz-FIOCRUZ, em que seus trabalhadores sem condições de arcar com os custos de transporte, ocuparam parte do terreno do Instituto e construíram suas casas na área em que hoje é conhecida como Parque Oswaldo Cruz. Posteriormente, esse território passa a ser ocupado em maioria por moradores removidos de cortiços da zona central da cidade, a partir das reformas urbanas pautadas em visões eurocêntricas/eugenistas, como a Reforma Pereira Passos iniciada em 1903 e o plano Agache desenvolvido entre 1927 a 1930.

Importante ressaltar que em grande maioria as pessoas removidas dos centros urbanos que foram residir em Manguinhos, eram pessoas negras, que com o processo de abolição sem reformas, passaram 
a ser excluídos, sendo impossibilitados de ter acesso à terra, ao trabalho, aos direitos políticos, ou seja, a condições de sobrevivência como pessoas "livres". Com a expulsão dos cortiços, foram obrigados a ocupar territórios sem infraestrutura, encostas, e assim formaram-se os territórios que hoje conhecemos como favelas ou morros. Com um processo de exclusão, a partir de discriminações diretas e indiretas, se criou uma estratificação social no qual o percurso da vida da população negra enquanto grupo social foi afetado (ALMEIDA, 2018, p.55), não à toa, a maioria da população residente em favelas na atualidade, são pessoas negras, segundo o Data Favela (2015, p.20) residem em favelas 12,3 milhões de pessoas, sendo $67 \%$ destas negras/os, mais da metade, 6,3 milhões sendo de mulheres, dessas 69\% são de mulheres negras.

Corroborando com tais dados, o perfil das 509 mulheres que realizaram o primeiro atendimento na Casa da Mulher de Manguinhos no ano de 2014, também foram em maioria mulheres negras, constituindo $74 \%$ das atendidas, e acrescido a isso encontramos a disparidade de classe, que em maioria eram mulheres em condição de pobreza, 35\% recebiam menos que um salário mínimo que era de $\mathrm{R} \$$ $724,00,33 \%$ não tinham renda e 30\% recebiam de 1 a 3 salários mínimos, nenhuma mulher atendida naquele ano recebia mais que 3 salários mínimos, ou seja, tínhamos $68 \%$ das mulheres atendidas em condição de pobreza.

Segundo dados da Escola Nacional de Saúde Pública Sérgio Arouca-ENSP (2011), residiam em Manguinhos 19.794 mulheres enquanto o número de homens era de 16.605, o que corrobora também com a afirmação de que as mulheres são maioria nas favelas. A população feminina representa 53\%, sendo maioria nas faixas etárias, exceto na faixa dos 10 a 14 anos, além disso 56\% das mulheres são chefes de família (Plano de Desenvolvimento Sustentável de Manguinhos, 2011).

Pode-se dizer que Manguinhos é o resultado do processo de gentrificação das cidades, produto de um processo histórico de segregação de classe, gênero e raça, com início nos primeiros anos do 
século XX, mas que perdura até os dias atuais, com a implementação de políticas urbanas que não respondem as necessidades da população e sim as necessidades do grande capital a partir do mercado imobiliário e da construção civil e que tem contribuído com a piora da vida das mulheres, especialmente das mulheres negras.

A Casa da Mulher de Manguinhos, fruto do Programa de Aceleração do Crescimento (PAC), foi fundada em 2009, no espaço do Centro Cívico, que concentrou equipamentos públicos voltados para a área de saúde, educação, cultura e lazer. Embora o discurso dos governantes transmitisse a ideia de que o PAC era um moderno projeto de Nação no qual realizava investimento econômico atrelado as políticas sociais, na prática grande parte das medidas adotadas pelo programa estava voltada para estimular o setor privado "através do aperfeiçoamento e agilização de licenças e marcos regulatórios, medidas de desoneração tributária e incentivos ao desenvolvimento tecnológico e fortalecimento das micro e pequenas empresas" (OLIVEIRA, 2016, p. 69).

O PAC Manguinhos foi marcado pela ausência de um projeto técnico voltado para a execução das suas obras sendo realizado a partir de um anteprojeto apresentado pelo governo estadual baseado no Plano de Desenvolvimento Urbano do Complexo de Manguinhos de 2004 encomendado pela Prefeitura, tal ação permitiu aos gestores aumentar orçamento de algumas intervenções, inviabilizar e postergar obras, incluir e retirar localidades do escopo das obras, ou seja, alterar a forma inicial prevista no projeto de acordo com a vontade política e econômica dos entes governamentais e dos interesses privados e escusos dos envolvidos (OLIVEIRA, 2016, p.69).

É nesse cenário que surge a Casa da Mulher de Manguinhos, instituição não prevista no conjunto de equipamentos sociais no projeto inicial do PAC (OLIVEIRA, 2016, p.62), criada em um espaço físico de $50 \mathrm{~m}^{2}$, divididos em uma cozinha, um banheiro e uma sala, sendo a sala organizada com os móveis para se tornar dois espaços, um de recepção 
e acolhimento e o outro para atender as usuárias, sendo que um armário e dois arquivos dividiam o espaço.

De acordo com o projeto inaugural a instituição tinha como objetivo: "Promover a expansão dos espaços de atuação das mulheres da comunidade de Manguinhos, melhorando sua situação social, econômica e política" (PEIXOTO, 2009, p.33). Mas, como realizar isso, sem estrutura física, orçamento e equipe técnica adequada? A Casa da Mulher de Manguinhos, assim como outras instituições do escopo do projeto do PAC Manguinhos, já nasceu precarizada, sem orçamento para sua manutenção e sem estrutura de recursos humanos, que possuía em maioria estagiárias, o que configurava o uso da modalidade de formação como meio para baratear a mão-de-obra, o que consequentemente promovia a fragilização da execução das ações.

Nesta inauguração é possível perceber o descaso do poder público no atendimento as mulheres em situação de precarização ou risco social, e nenhum comprometimento em enfrentar à violência de gênero contra às mulheres residentes em territórios de favela, embora em sua inauguração o discurso das autoridades ressaltassem a importância da Lei Maria da Penha e desta instituição no enfrentamento à violência, com sua estrutura, percebe-se os limites da concepção.

Em 2012, quando a instituição passa a ter equipe técnica/administrativa mínima completa conforme Norma Técnica dos Centros de Referência de Atendimento à Mulher em situação de Violência (2006), ela passa a ser reconhecida pela rede de atendimento às mulheres em situação de violência como um equipamento especializado para oferecer assistência às mulheres.

$\mathrm{O}$ conceito de enfrentamento à violência contra às mulheres, adotado pelo Brasil, diz respeito à:

implementação de políticas amplas e articuladas, que procurem dar conta da complexidade da violência contra as mulheres em todas as suas expressões. $\mathrm{O}$ enfrentamento requer a ação conjunta dos diversos setores envolvidos com a questão (saúde, segurança 
pública, justiça, educação, assistência social, entre outros), no sentido de propor ações que: desconstruam as desigualdades e combatam as discriminações de gênero e a violência contra as mulheres; interfiram nos padrões sexistas/machistas ainda presentes na sociedade brasileira; promovam o empoderamento das mulheres; e garantam um atendimento qualificado e humanizado àquelas em situação de violência. Portanto, a noção de enfrentamento não se restringe à questão do combate, mas compreende também as dimensões da prevenção, da assistência e da garantia de direitos das mulheres, que compõe os Eixos Estruturantes da Política Nacional de Enfrentamento à Violência contra as Mulheres (POLÍTICA NACIONAL DE ENFRENTAMENTO A VIOLÊNCIA CONTRA AS MULHERES, 2011, p. 25)

Compreendemos que as ações de enfrentamento à violência contra às mulheres perpassam por outros campos que não sejam só o combate, que ocorre pela criação e cumprimento de normas penais que garantam a punição e responsabilização dos autores de violência. Os Centros de Referência de Atendimento à Mulher em situação de Violência -CRAMs, fazem parte do Eixo de Assistência da Política, segundo a Norma Técnica do CRAMs (2006) eles tem a função de:

Os Centros de Referência são estruturas essenciais do programa de prevenção e enfrentamento à violência contra a mulher, uma vez que visa promover a ruptura da situação de violência e a construção da cidadania por meio de ações globais e de atendimento interdisciplinar (psicológico, social, jurídico, de orientação e informação) à mulher em situação de violência. Devem exercer o papel de articuladores dos serviços organismos governamentais e não-governamentais que integram a rede de atendimento às mulheres em situação de vulnerabilidade social, em função da violência de gênero (NORMA TÉCNICA DE UNIFORMIZAÇÃO DOS CRAMS, 2006, p. 11). 
Como mencionado anteriormente, os territórios de favela têm cor, classe e gênero, são ocupados em maioria por mulheres negras em condição de pobreza, como sair da situação de violência sem autonomia econômica, em uma sociedade marcada pela discriminação racial, residindo em um território que é fruto da violação estatal, em uma sociedade patriarcal? Como promover ações de enfrentamento à violência contra às mulheres, em um território ocupado também por outros poderes armados, que não só os do Estado?

$\mathrm{O}$ atendimento às mulheres residentes em favelas visando enfrentar à violência de gênero, necessita obrigatoriamente perpassar por áreas que transversalizam o enfrentamento da violência contra às mulheres e promova a ampliação da sua cidadania e o acesso a direitos. É preciso reconhecer e enfrentar também as diversas outras violações que perpassam a vida dessas mulheres, compreender de forma interseccional as opressões que as atingem.

Além do atendimento social, psicológico e jurídico individual às mulheres nos casos de violência doméstica, familiar e sexual, na Casa da Mulher de Manguinhos eram promovidas ações compreendendo a integralidade da vida das mulheres e tudo que se relacionava a elas, então os atendimentos realizados iam de atendimentos sobre orientações para enfrentar a violência doméstica à orientações sobre direitos previdenciários, direitos do consumidor, acesso a saúde, orientações sobre os direitos das que tinham familiares de pessoas que estavam no sistema prisional ou no sistema socioeducativo, como com orientações sobre como identificar aonde está o filho ou o companheiro após a apreensão ou o direito para a realização das visitas, dentre tantas outras demandas. Somado a isso, também eram realizados grupos de convivência semanal, parceria com serviços de saúde ${ }^{4}$, parcerias com empresas e instituições para acesso a vagas de trabalho, cursos de

${ }^{4}$ Em 2015, a Casa da Mulher de Manguinhos realizou parceria com o projeto Apolônias do Bem, que oferece tratamento odontológico gratuito para mulheres que vivenciaram situações de violência e tiveram a dentição afetada. Disponível em http://turmadobem.org.br/br/nossos-projetos/apolonias-do-bem/ . Acessado em 10 de janeiro de 2019. 
qualificação ${ }^{5}$, fomento a participação social ${ }^{6}$ das mulheres, e outras atividades.

Assim, foi a partir da compreensão e reconhecimento das relações sociais estabelecidas nesse território, que foi possível, de forma contraditória, mesmo sem estrutura adequada e uma equipe ampliada, após seis anos, em 2015, essa instituição se tornar a segunda instituição coordenada pelo governo estadual do Rio de Janeiro, com maior quantidade de atendimentos realizados, só ficando atrás do Centro Integrado de Atendimento à Mulher-CIAM Márcia Lyra, que existe desde o início de 2000 no Centro do Rio de Janeiro e que é referência para a área em todo o estado (Subsecretaria de Políticas para as Mulheres, 2015, p. 14).

A PNEV (2011) tem quatro eixos estruturantes: prevenção, combate, assistência e garantia dos direitos das mulheres, a partir dos dados apresentados, podemos dizer que o único eixo em que parece ter sido pouco acessado é o eixo do combate, que necessita da manifestação expressa das mulheres para acionar a segurança pública, o que significa passar pelo atendimento à uma delegacia de polícia.

Historicamente, as violências institucionais, são expressas pela atuação dos agentes de segurança pública, embora não sejam somente estes a realizá-las, tais fatos ficam explícitos no relatório Circuito de Favelas por Direitos da Defensoria Pública do Rio de Janeiro (2018), que nos evidencia às violações sofridas pelas mulheres residentes em favela com a intervenção militar:

Tem sempre três, quatro mais nervosos e mais abusados e a gente mulher sofre mais com isso. Minha filha estava tomando banho, dois policiais

\footnotetext{
5 É possível identificar várias ações realizadas pela Casa da Mulher de Manguinhos nessa perspectiva. Disponível em: https://www.facebook.com/Casa-da-Mulher-deManguinhos-180655578713386/ . Acesso em 10 de janeiro de 2019.

6 Realização da Conferência Livre de Políticas para às Mulheres em Manguinhos, realizada pela OMA em parceria com a Casa da Mulher de Manguinhos e outras instituições. Disponível em: https://portal.fiocruz.br/noticia/pre-conferencia-livremulheres-de-manguinhos-discute-politicas-para-mulheres . Acesso em 10 de janeiro de 2019.
} 
saíram entrando na minha casa olhando tudo, um foi no banheiro e abriu a cortina com ela pelada dentro. Ela gritou e ele disse "cala a boca sua piranha!

Mora lá em cima uma senhora cega. Ela contou que um PM entrou na casa dela já agredindo ela com um tapa na cara, ela guardava $\mathrm{R} \$ 700,00$ em casa. Eles pegaram o dinheiro dela.

Uma senhora de 68 anos, já tendo sofrido 3 infartos e 1 AVC, estava sentada na porta de casa e nos relatou vários episódios de invasão do seu domicílio por policiais militares. Uma vez, ela estava sentada na porta de casa quando um policial insistiu para entrar, mas a casa tem dois cachorros bravos. Como a senhora idosa estava sozinha e não tinha forças para prendê-los, o PM começou a insultá-la. Eles fizeramna se levantar de sua cadeira para subir nela e, assim, subir no muro. Quando o PM fez isso, o cachorro quase pulou em cima dele, fazendo com que desistisse da empreitada. Em uma outra vez, eram $6 \mathrm{~h}$ da manhã e seu neto foi acordado com um fuzil na cara e PMs revirando coisas na casa. Infelizmente, essa senhora possuía muitas outras histórias de violação de domicílio que não fui capaz de anotar tudo. É uma ação que se repete inúmeras vezes e não importa se é uma senhora idosa (RELATÓRIO DO CIRCUITO FAVELA POR DIREITOS DA DEFENSORIA PÚBLICA DO ESTADO DO RIO DE JANEIRO, 2018, p. 5-6).

Segundo os dados do Dossiê Mulher (2018, p.59), a Área Integrada de Segurança Pública- AISP 22 que abrange o bairro de Manguinhos e de outros territórios de favela como a Maré, realizou uma quantidade de registros de ocorrência referente ao crime de lesão corporal dolosa muito próximo ao número de registros da AISP 02, que abrange bairros como a Urca e o Cosme Velho, que possuem os melhores índices de desenvolvimento humano-IDH do estado. A AISP 22 registrou 485 ocorrências e a AISP 02 428. Também não foram 
encontrados registros de atendimento às mulheres na Casa da Mulher de Manguinhos no ano de 2015, que informasse que havia ocorrido a realização de registro de ocorrência nas delegacias.

No que diz respeito a produção de dados sobre à situação de violência que atinge às mulheres residentes no território de Manguinhos, buscamos dados em vários documentos oficiais e órgãos governamentais: Sistema de Informação de Agravos de NotificaçãoSINAN7, Dossiê Mulher (2015, 2016, 2017, 2018)², relatórios do Teias Escola Manguinhos ${ }^{9}$, mas não foi possível encontrar; nos relatórios divulgados pela Estratégia de Saúde da Família em Manguinhos, não são disponibilizados os dados que tratam da violência doméstica e familiar e outras violências contra às mulheres, o Sistema de Informações e Mortalidade-SIM também não aponta de forma específica os casos de morte por violência de gênero contra mulheres, destaca somente as mortes por causas externas que no território assumem o índice de $18,9 \%$ no ano de 2010 , sendo quase $20 \%$ mortes do sexo masculino e o sexo feminino atingindo um pouco mais de $5 \%{ }^{10}$.

Em seu escopo teórico, a PNEV (2011) prevê a importância de enfrentar à violência de gênero tendo como base a interseccionalidade das opressões, especialmente de raça, classe e geração, mas no Brasil vemos o aumento do homicídio de mulheres negras e o decréscimo do assassinato de mulheres brancas (ATLAS DA VIOLÊNCIA, 2018, p. 51), quando analisada as ações de implementação para o enfrentamento ao fenômeno a partir dos planos de políticas para as mulheres nota-se o enfrentamento ao racismo constituído basicamente por ações de formação e capacitação, o que pelos dados apresentados tem demonstrado ineficácia.

\footnotetext{
7 Disponível em: http://portalsinan.saude.gov.br/dados-epidemiologicos-sinan . Acesso em 20 de janeiro de 2019.

8 Nesse documento parece existir uma subnotificação na região, que se evidencia como o não acesso às mulheres residentes em favelas as Delegacias.

9 Programa de saúde da família do território de Manguinhos.

10 Disponível em: http:/ / andromeda.ensp.fiocruz.br/teias/situacao_de_saude. Acesso em 20 de janeiro de 2019.
} 


\section{Conclusão}

Embora exista no arcabouço teórico da PNEV (2011) o reconhecimento da diversidade da vida das mulheres, quando analisamos sua implementação identificamos que ainda existem limites para a sua plenitude, bem como também existem possibilidades para o desenvolvimento de um atendimento mais qualificado às mulheres no que tange o enfrentamento da violência de gênero.

A implementação da PNEV (2011) para as mulheres residentes em favelas, nos evidencia que o atendimento às mulheres de forma integral é possível e necessário. Somado a isso a vida dessas mulheres são uma potência que nos trazem a importância de compreender que o enfrentamento à violência de gênero deve perpassar obrigatoriamente pelo enfrentamento de diversas outras opressões como de raça e classe, assim, se identifica que não é possível reduzir os índices de violência contra às mulheres, negando a diversidade destas. Os Centros de Referência de Atendimento as Mulheres em Situação de Violência tem um papel fundamental na rede de atendimento na promoção da diversidade e na possibilidade de dar visibilidade as violências que atualmente não são criminalizadas, como a violência de gênero institucional.

A Lei Maria da Penha, é um avanço, não somente pelo reconhecimento das diversas formas de violência contra as mulheres ou pela criação de juizados especializados para julgar casos de violência doméstica e familiar, mas principalmente, pelo direcionamento estrutural com a qual ela trata o problema da violência contra as mulheres, cabe aos profissionais, ao poder público e a sociedade em geral ampliar sua implementação e ultrapassar a lógica punitivista. 


\section{Referências}

AGAMBEN, Giorgio. Estado de exceção. São Paulo, Boitempo. 2004.

ALMEIDA. Suely Souza de. Essa violência mal-dita. In: ALMEIDA, S. (Orgs.). Violência de gênero e políticas públicas. Rio de Janeiro: Editora UFRJ, 2007, p. 23-41.

ARAÚJO. Antônia Gabriela P. de. O que a branquitude tem a ver com o caso de Marielle Franco? Geledes, 2018. Disponível em: https:/ / www.geledes.org.br/o-que-branquidade-tem-haver-com-ocaso-de-marielle-franco/ . Acesso em: 18 jun. 2018.

AZEVEDO, Celia Maria Marinho de. Onda negra, medo branco: o negro no imaginário das elites do século XIX. Rio de Janeiro: Paz e Terra, 1987. p. 267

BRASIL. Secretaria Especial de Políticas para as Mulheres. Política Nacional de Enfrentamento à Violência contra as Mulheres. Brasília: 2011. Disponível

em: http://www.spm.gov.br/sobre/publicacoes/publicacoes/2011/poli tica-nacional . Acesso em: 15 jun. 2018.

BRITO, Maíra de Deus. História de vida de mães que perderam os filhos assassinados: "uma dor que não cicatriza". 2017. Dissertação (Mestrado em Direitos Humanos e Cidadania) - Universidade de Brasília, Brasília, 2017.

CAMPOS, Andrelino. Do quilombo à favela: a produção do "espaço criminalizado" no Rio de Janeiro. 5.ed. Rio de Janeiro: Bertrand Brasil, 2012.

DAVIS, Angela. Mulheres, cultura e política. 1. ed. São Paulo: Boitempo, 2017.

DEFENSORIA PÚBLICA DO ESTADO DO RIO DE JANEIRO. Relatório Circuito de favelas por direitos 2018. Disponível em: http:// sistemas.rj.def.br/publico/sarova.ashx/Portal/sarova/imag em-

dpge/public/arquivos/Relato\%CC\%81rio_Final_Circuito_de_Favel as_por_Direitos_v9.pdf. Acesso em: 15 jan. 2019.

FÓRUM DE JUVENTUDES DO RIO DE JANEIRO. Relatório final do projeto militarização das favelas: impactos na vida dos jovens negros e 
negras do fórum de juventudes do RJ. 2015. Disponível em: http://juventude.gov.br/articles/participatorio/0012/5008/RELAT _RIO_FINAL_DO_PROJETO_MILITARIZA_O_DAS_FAVELAS.pd f. Acesso em: 15 jun. 2018.

INSTITUTO DATA FAVELA. As favelas no Brasil: percepções e perspectivas. Rio de Janeiro. 2015. Disponível em: http:// datasebrae.com.br/documentos2/pesquisas/Nova\%20Favel a\%20Brasileira/Apresentacao_2o\%20Forum\%20Favela_Consolidado _Sebrae.pdf. Acesso 22 jun. 2018.

IPEA. Atlas da Violência 2018. Rio de Janeiro, 2018. Disponível em: http://www.ipea.gov.br/portal/images/stories/PDFs/relatorio_in stitucional/180604_atlas_da_violencia_2018.pdf . Acesso em: 20 jan. 2019.

MBEMBE, Achille. Necropolítica. Revista Arte $\mathcal{E}$ Ensaios do PPGAV/EBA/UFRJ, n. 32, dez. 2016. Disponível em: https:/ / revistas.ufrj.br/index.php/ae/article/viewFile/8993/7169. Acesso em: 10 out. 2018.

MORAES, Cláudia Orlinda R. de; MANSO, Flávia Vastano. (Org.) Dossiê Mulher 2018. Rio de Janeiro: Instituto de Segurança PúblicaISP/RJ. 2018. Série Estudos. Disponível em: http://arquivos.proderj.rj.gov.br/isp_imagens/uploads/DossieMul her2018.pdf. Acesso em: 10 jan. 2019.

PIEDADE, Vilma. Dororidade. Rio de Janeiro: Editora Nos, 2017.

POUGY, Lilia Guimarães. Direitos Humanos, Democracia e Políticas Públicas com Recorte de Gênero. In: Fazendo gênero 9 diásporas, diversidades, deslocamentos. Florianópolis, 2010. Anais Eletrônico. Florianópolis/SC, 2010.

QUIJANO, Anibal. Colonialidade do poder, eurocentrismo e América Latina. In: LANDER, E. (Org.). A colonialidade do saber: eurocentrismo e ciências sociais. Perspectivas latino-americanas. Buenos Aires. CLACSO. 2005. p. 117-142.

RAMOS, Silvia (Coord.). À deriva: sem programa, sem resultado, sem rumo. Rio de Janeiro: Observatório da Intervenção/CESec, abril de 2018. Disponível em: https://www.ucamcesec.com.br/wpcontent/uploads/2018/04/Relat\% C3\%B3rio-01- 
Observat\%C3\%B3rio-da-Interven \%C3\%A7\%C3\%A3o_final.pdf Acesso em: 10 jan. 2019.

SUBSECRETARIA DE POLÍTICAS PARA AS MULHERES DO ESTADO DO RIO DE JANEIRO. Perspectivas das politicas para as mulheres no Estado do Rio de Janeiro. Apresentado na audiência realizada pela comissão parlamentar de inquérito da Alerj destinada investigar as causas da violência contra a mulher no Estado. Rio de Janeiro: abril, 2015. 